\title{
Confirmatory factor analysis: model testing of financial ratios with decision support systems approach
}

\author{
T. Husain ${ }^{1}$, Maulana Ardhiansyah ${ }^{2}$, Dedin Fathudin ${ }^{3}$ \\ ${ }^{1}$ Departement of Information Systems, STMIK Widuri, Indonesia \\ ${ }^{2,3}$ Department of Informatics Engineering, Universitas Pamulang, Indonesia
}

\section{Article Info \\ Article history: \\ Received Jun 5, 2020 \\ Revised Nov 25, 2020 \\ Accepted Jan 23, 2021}

\section{Keywords:}

Confirmatory factor analysis

DSS approach

Goodness-of-fit

Mathematical models

\begin{abstract}
The decision support systems approach can be developed into both computer-based and quantitative analysis tools. This research uses a model test with a confirmatory factor analysis (CFA) technique on matrix covariance against structural equation modelling (SEM) methods to measure financial ratios. Decision support system (DSS) analysis uses numerical calculations aided by mathematical models through six phases. The first three phases of a structured approach to building multivariate models and the next three phases, namely estimation, interpretation, and validation, are developing from data input that has been selected using LISREL version 8.72. The financial ratio's testing model with a CFA approach derived into a mathematical (quantitative) model can explain the complexity of the relationship between the goodness-of-fit models (GOF) with a different approach from prior research. The goodness-of-fit test results in this study produced scores on each of the financial ratio measurement models at an accuracy level of CR of 78.49, TATO of 1.26, DER of 41.41, ROA of minus 0.033 , and PBV of 540.92. This means that PBV has the highest standardized loading factors to determine the measurement of financial ratios. The CFA measurement based on SEM can be used to make appropriate decisions and combine a model comparison and redevelopment of the CFA technique and model testing with other software such as SPSS, PLS, AMOS, and others.
\end{abstract}

This is an open access article under the CC BY-SA license.

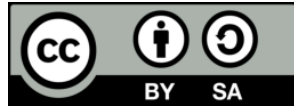

\section{Corresponding Author:}

T. Husain

Departement of Information Systems

STMIK Widuri

Palmerah Barat Street No. 353, South Jakarta-12210, Indonesia

Email: thusain050686@gmail.com

\section{INTRODUCTION}

Decision support systems (DSS) approach can be developed into approaches or methods, both computer-based systems or by developing methods or standards for quantitative analysis tools. This function can be used to solve problems in making semi and unstructured decisions. According to Sharda, Delen, and Turban [1], that these key DSS abilities and characteristics permit decision-makers to make better, further orderly decisions promptly. Modeling implies transfiguring the real-world hassle into a relevant prototype structure (model); Turban et al. argue that mathematical model is one of the approaches derived from scientific management processes to describe a real-world problem with prototypes and algebraic expressions so that modeling solutions can be solved using fast and efficient approaches [2]. The classical statistical approach has focused on predicting observations through quantitative analysis, in particular, mathematical modeling based on the relationship of factors. [3]. Factor analysis is a statistical approach with a dual variable inspection technique that determines the main components and manifests the interrelations among variables. According 
to Hair et al., factor analysis has the main objective to discover a scheme designate the output carried in the quantity of the native variables inside a recent information assemblage of refine [4]. Furthermore, to carry out a confirmatory factor analysis, it can use raw data as input data in the form of covariant matrices or temporary correlation matrices to confirm the factor must first define latent constituents because these factors cannot be measured directly but through indicators or measurements that represent the construct [5].

Several recent studies [6]-[9] have suggested that this research is a multivariate model using the Pair-Copula approach that functions of two variables simultaneously using a hierarchical model construct, bivariate copulae, and copula models (R-vine). Conditioning using simple building blocks, then canonical vine copulas involving both observed and latent variables allows tail, asymmetric, and non-linear dependence. Using a goodness-of-fit index for the least-squares modeling to simulate and compare the index with the model fit in the structural equation model and also a new goodness-of-fit approach of simulation Rvine specifications. According to Henseler and Sarstedt, the results can validate how well a model explains data differences [10]. The model, structural equation modelling (SEM), with maximum likelihood estimation (MLE) approach according to with standard error (SE) operates a model specification test and information matrix with the likelihood ratio (LR) statistic from Alberto Maydeu-Olivares research, these finding that is optimizing the SE's calculated in concern a mean-and variance alter LR script statistic for the look ahead to information matrix [11]. The customer satisfaction model of leasing enterprise users to entail 50 respondents of the tempt a sample in conjunction with the purpose of Pilai, Lambda, F, and Wilk's test with the assist of SPSS from Rizkiana and Hendikawati research, these findings that three-factor of discriminant analysis far side of the $\mathrm{z}$-score proceeds of the attestation which appeared the precision score of the model which somewhat upper at 54 percent [12].

The use of covariance-based simulation models involves 95 percent confidence intervals with sample $n=100$ use dependent variables in pairs in determining covariances, such as the Vale-Maurelli approach that focuses on identifying and improving skewness scores and univariate kurtosis with covariance structures from Grønneberg and Foldnes research, these findings that when covariance is weakly correlated, results based on the method other simulations will potentially give similar results [13]. Computational cognitive engineering model compares differences in models through criteria based on predictive performance and generative models to see feasibility and simulations with a cognitive scientific approach from Palminteri et al., research. The results of computational engineering models can assist in realizing the mechanisms that manage thoughts and behavior to the other side of the generation of algorithms in the reproduction of the impact of cognitive aspects viz. one's behavior [14]. Botes et al. argue that arranged decision support systems to get a meter of backdated energy efficiency modeling options objectively operated to assist in the process of consideration in the decision-making using the weighted-sum method. These findings of the financial comparison appeared that section $12 \mathrm{~L}$ tax incentive of the monetary worth of the ascendancy amount of 10 percent also 33 percent if no medium were on hand to obtain the last model [15]. Shkeer and Awang argue that the Marketing Information System set up with a factor analysis study involving 100 respondents through KMO and Bartlett's test and component matrices from each item and internal reliability to measure instruments in the decision-making process resulting ineffectiveness in measuring marketing decision support systems [16]. T. Husain and Maulana Ardhiansyah argue that the simulation model of Financial Ratio can explain the comparison of the integrated model testing with DSS a particular statistical approach, i.e., Pair-Sample T-Test [17].

In the present study, the mathematical modeling based on the relationship of factors through CFA technique and SEM methods uses to confirm whether the construct tested has a standardized loading factor (SLF) score that meets the requirements for decision-making. This study uses a different approach from prior studies, where factor analysis based on SEM has not been used in previous studies. This model is considered powerful, which can explain the model's assessment through the stages of the SLF and goodness-of-fit (GoF) test. The option of research subjects is driven by a few studies of the CFA technique test based on the decision support system approach in the research of social science categories in Indonesia. The previous research is still limited and dominated by research on the exact or mathematical science studies related to DSS.

Therefore, the importance of this research is to provide ideas to specify and test the model in a new framework for future research for a researcher. However, the current study tries to another focus, where covariance values through the CFA technique serve as a guide in developing a model DSS. The research aims to adapt the framework for focusing on secondary data, i.e., the release of the Indonesian stock exchange (IDX) which companies that conduct initial public offerings (IPO) as fifty-five new issuer's in 2019 by adding data from the previous year's, in 2018 [18], who have met the requirements for using the maximum likelihood estimation (MLE) technique in SEM. 


\section{RESEARCH METHOD}

This study uses an interdependent method that aims to reduce the original variables to be analyzed. The information used is still owned and developed, and it is known as an abstract concept [19]. DSS analysis utilizing numeral calculations assisted with arithmetic calculation or other quantitative models that can be expanded with a covariance matrix analysis approach with modeling. The developed paradigm consists of six stages. The first three stages of the structured approach are to construct a multivariate model. The next three stages are to estimate, interpret, and validate the factor model. These are additional steps to assist in selecting substitute variables, computational factor scores, or creating summary scales, for application to other multivariate techniques [4]. Table 1 is showing the definition and measurement model, Figure 1 is showing the framework of CFA using quantitative model and DSS approach and Table 2 is showing characteristic of fit indices.

Table 1. The definition and measurement model [20]

\begin{tabular}{|c|c|}
\hline Definition & Measurement \\
\hline $\begin{array}{l}\text { Liquidity Ratios is appeared a firm's } \\
\text { liquidity in giving short-range } \\
\text { obligations or indebtedness that is } \\
\text { scheduled. }\end{array}$ & $\mathrm{CR}=\frac{\text { Current Assets }}{\text { Current Liabilities }}$ \\
\hline $\begin{array}{l}\text { Activity Ratio's are used to measure one } \\
\text { of the efficiencies which the firm using } \\
\text { an asset to generate sales }\end{array}$ & $\mathrm{TATO}=\frac{\text { Net Sales }}{\text { Average Total Assets }}$ \\
\hline $\begin{array}{l}\text { Debt ratios are used to measure one of } \\
\text { the enlargements of risk and return } \\
\text { through the use of fixed cost financing }\end{array}$ & $\mathrm{DER}=\frac{\text { Total Debt }}{\text { Shareholders'Equity }}$ \\
\hline $\begin{array}{l}\text { Profitability Ratio's are used to measure } \\
\text { one of the effectiveness levels of } \\
\text { management in yielding profits }\end{array}$ & $\mathrm{ROA}=\frac{\text { Net Income }}{\text { Total Assets }}$ \\
\hline $\begin{array}{l}\text { Market share ratios which are used to } \\
\text { enumerate the contemporary share price, } \\
\text { to special accounting values }\end{array}$ & $\mathrm{PER}=\frac{M P \text { per Shares of } C / S}{\text { Earnings per Share }}$ \\
\hline
\end{tabular}

Financial ratios modeling with matrix covariance approach is compute as:

$$
\begin{aligned}
& \mathrm{R}=\lambda \xi+\delta 1 \\
& \mathrm{TATO}=\lambda \xi+\delta 2 \\
& \mathrm{DER}=\lambda \xi+\delta 3 \\
& \mathrm{ROA}=\lambda \xi+\delta 4 \\
& \mathrm{PER}=\lambda \xi+\delta 5
\end{aligned}
$$

Model estimation, interpretation, and validation are developing from data input that has been selected using LISREL version 8.72. This research uses a maximum likelihood estimation (MLE) technique, which requires ranges from 50-200 data observations. This research's objective invite involves a mathematical simulation model using data mining and structural equation modeling (SEM).

Several guidelines were used to assess the suitability index based on the research model with separate sample sizes, model changes, and error rates in model specifications to identify the various suitability indices [4]. If the developed model has a reasonable error approximate to resolve whether the model can produce the measurement output further tested or return to the previous phase [21]. 


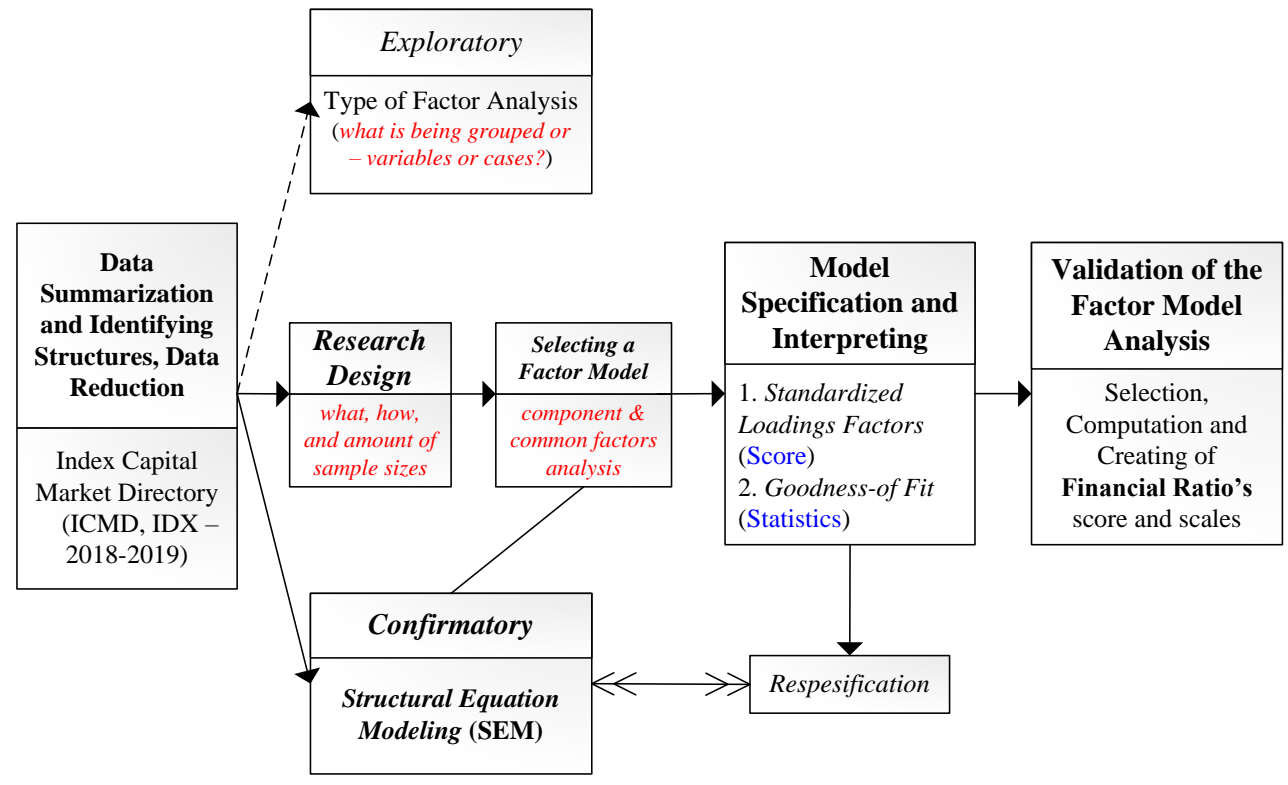

Figure 1. The framework of CFA using quantitative model and DSS approach [3], [4], [20]

Table 2. Characteristic of fit indices

\begin{tabular}{cc}
\hline $\begin{array}{c}\text { Number of Stat. (Observe } \\
\text { variables }-m)=12\end{array}$ & $\begin{array}{c}\text { Index Cut off values based on model } \\
\text { characteristics }\end{array}$ \\
\hline 22 & Insignificant p-values predicted \\
CFI $/$ TLI & 0.97 or preferable \\
RNI & May not diagnose misspecification well \\
SRMR & Biased upward, use more indices \\
The RMSEA & Worth $<0.08$ by CFI $=0.97$ or higher \\
\hline
\end{tabular}

\section{RESULTS AND ANALYSIS}

\subsection{Data summarization, identifying structures and data reductions}

The purpose of summarizing data in defining several specific factors is to achieve the representation of many constructs. This summarization process explores the combination of structures that have been defined in the measurement of the interrelationships between factors that allow for the specification of a small number of dimensions (factors) that illustrate part of the genuine variable. Data reduction also depends on factor loading but for identifying factors for further analysis with other techniques or forming estimations of themselves (factor scores or addition scales), which then restore the genuine variables after the analysis phase. This study uses five financial ratio measurement factors consists of CR, TATO, DER, ROA, and PER (proxy) obtained from prospectus reports and financial statements of fifty-five IPO companies in 2019 and reduced by two company so that the observation data that meet the subset of representative variables in this phase is $53 \times 2$ years of observation.

\subsection{Designing a factor analysis model}

Factor analysis is designed as a basis for calculating data input and classification, for the grouping of observational data, measurement properties, and variables, as well as using the sample size requirements needed to analyze decision-making. The sample calculation in the previous phase was 106 data observations that have fulfilled the requirements in the estimation technique based on maximum likelihood estimation (MLE). Furthermore, consideration of these components' selection was conceptualized into a model with a confirmatory factor analysis (CFA) technique. Figure 2 is showing path diagram: initial model. 


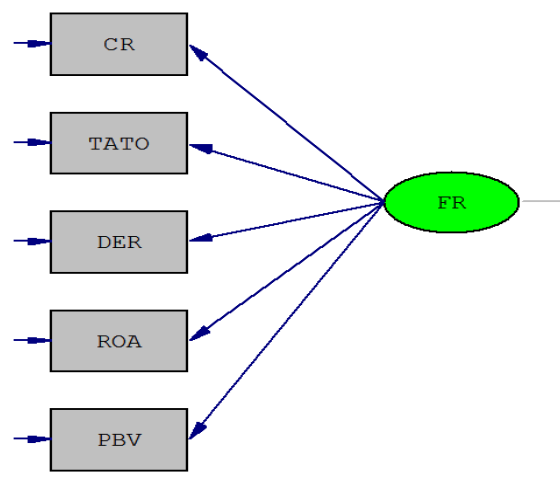

Figure 2. Path diagram: initial model

\subsection{Model specification and interpreting}

Model specifications designed in the path diagram are converted into covariance matrix equation structures consisting of:

$\lambda=$ covariance matrix between loading indicators of a factor

$\xi=$ the construct of each factor

$\delta=$ measurement error of each factor

The estimated models in this study were tested using the LISREL version 8.72 software. The model specification starts with the item validity test (indicator) to confirm a factor load standard with the provisions that if the $\mathrm{t}$-value $\mathrm{t}$-critical or standardized loading factors (SLF) value was more than 0.5 , then the indicator is declared valid or vice versa. Next, an evaluation of factor criteria carried out with an estimated model based on three measurement criteria, consists of absolute, incremental, and parsimonious fit measures (overall model fit) or known as goodness-of-fit statistics (GOF).

\subsection{Validation/deployment model}

The evaluation stage is executed pass two sub-tests i.e.,

- Standardized loading factors

$\mathrm{CR}=0.27 \mathrm{FR}+78,49$

TATO $=-0.055 \mathrm{FR}+1,26$

$\mathrm{DER}=0.29 \mathrm{FR}+41,41$

$\mathrm{ROA}=0.22 \mathrm{FR}-0,033$

$\mathrm{PBV}=-1.65 \mathrm{FR}+540,92$

Financial Ratio's gives a very impact on the accuracy of each measurement, including CR of 78.49, TATO of 1.26 , DER of 41.41 , ROA of only minus 0.03 , and PBV of 540.92. This means that PBV has the highest standardized loading factors to determine the measurement of Financial Ratio's. Figure 3 is showing path diagram: measurement model.

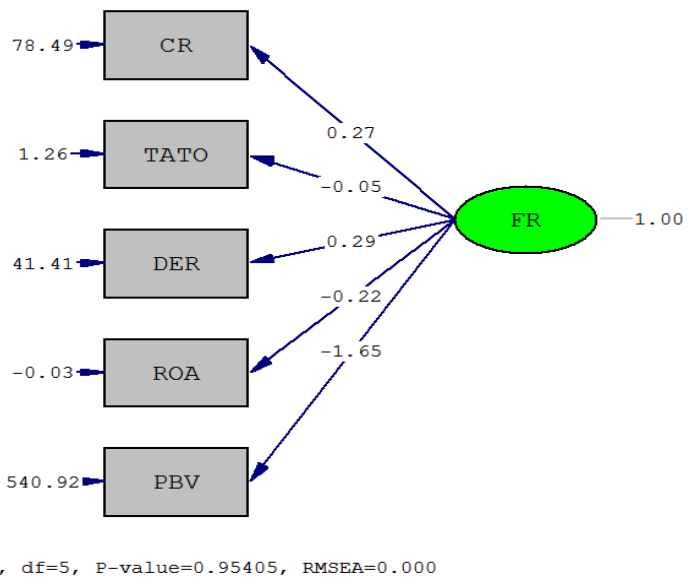

Figure 3. Path diagram: measurement model 
- Goodness-of-fit statistics (GoF)

Chi-square test produces a score of 1.10 with a p-value of 0.95405 . The CFI/TLI test yields a score of -8.82, which means it shows poor-fit. A standardized RMR 0.026 with an RMSEA of 0.00 results in a close-fit index. GFI and AGFI values of 1.00 also produce a close-fit index.

\subsection{Analysis}

The CFA technique is operated to prove the accuracy of the model development value in this research through summarization, design, specification, and validation stages on the DSS approach passed down inside statistical in SEM with financial ratio's objects. These illustrations explain that designing a path diagram for measurement properties and detecting errors in the use of measurements at an early stage. Hereafter, it specifies the design for the next stages to convert into a covariance matrix to interpret a forwarding decision-making model. In this research, the CFA technique using or known as first-order confirmatory in SEM used to see which measurements meet the factor load requirements. If the value is more than 0.5 , then the measurement is considered valid or vice versa. Furthermore, goodness-of-fit (GoF) was executed based on the three criteria above to assess whether the model proposed in this study could be continued at the deployment stage or not. If it does not meet the model suitability assessment criteria index, then a re-specification or modification indices step can be made through a recommendation from the output when using the LISREL Version 8.72 application with change the initial syntax by correlating a pair of values between error variances. This finding presents the value of RMSEA as a basis for decision making to validate the model, which requires a value of less than 0.08 .

Several studies show findings with each approach to answer research problems, such as the PairCopula approach by a hierarchical model construct with assessment through observed and latent variables [6]-[8]. The same is the case with the usage of GoF to explain a model; however, it uses an approach to partial least squares path modeling and also Kendall's-T copula model (R-vine) [10], [9] while this research uses a CFA technique and also adopted by the MLE approach but in this study did not calculated with variance alter LR and a mean test statistic [11]. Moreover, according to determine the significance of the function discriminant and testing average difference between several groups, this is also the same at the specification stage for testing the quality of the proposed measurement instrument [12], while this research uses an SLF confirmatory technique.

Covariance models with vine to anything (ViTA) were developed based on a multivariate distribution known as the R-Vines concept with high-level control specifically for the need data with nonnormality multivariate through the skewness and kurtosis score [13], while this research uses a GoF score viewed based on clause greater than 0.5 (p-values; Chi-Square score). With computational cognitive modeling, expectant models' simulation is obligatory to counterfeit the models and support definite cognitive function claims. However, they overlooked their predictive performance [14], while this research uses a CFI/TLI test yield score that is $-8,82$ viewed based on clause greater than 0.97 so it's very different from that clause. A systematic DSS as evaluation ingredient modeling as a base for decision-making used to a weighted-sum method to pick a final model which uses the monetary worth of the Section 12L tax incentive factor with a score between 0.1 to 0.33 [15], while in this research uses an RMR score that is 0.026 viewed based on a clause that meets the requirements is less than same with 0.08 . The construct of marketing DSS with exploratory factor analysis (EFA) and KMO and Bartlett's test with yield valid and reliable instrument which is similar to this research looking at Chi-Square score and p-values [16], while pair-sample T-test with a yield of normality and Levene's test is evaluation and assessment of the model with the DSS approach as a comparative study [17]. Based on the above analysis, the CFA measurement on an SEM basis is considered to answer or represent the accuracy of several results of previous studies. DSS abilities permit decisionmakers to make preferable, orderly decisions promptly if conjointed with CFA measurement for specification modeling.

\section{CONCLUSION}

The financial ratio testing model with a CFA approach attain into a mathematical (quantitative) model can describe the complexity of the link betwixt the goodness-of-fit model (GOF). The determination of the number of samples ranging from 50-200 is suitable using the maximum likelihood estimation (MLE) technique. Chi-square statistics $\left(\chi^{2}\right)$ of 1.10 with a p-value greater than 0.5 and the RMSEA score that shows a model that meets the close-fit criteria is the basis or reference that the model does not need to be carried out re-specification or improvement. The goodness-of-fit test results in this study produced scores on each of the financial ratio measurement models at an accuracy level of CR of 78.49, TATO of 1.26, DER of 41.41, ROA of minus 0.033 , and PBV of 540.92. This means that PBV has the highest standardized loading factors to determine the measurement of Financial Ratio's. 
The measurement of CFA based on SEM can be used as a consideration in making appropriate decisions. This research proposes practical resolves for hereafter investigation that integrate consolidate a model appeal and redevelopment of the CFA so that model testing can be useful for the denomination of how well another path model can describe distinct sets of data and use other software such as SPSS, PLS, AMOS, and others.

\section{REFERENCES}

[1] Ramesh Sharda, Dursun Delen, Efraim Turban, Business Intelligence and Analytics: Systems for Decision Support, 10th ed. NJ: Pearson, 2015.

[2] Efraim Turban, Jay E. Aronson, Ting-Peng Liang, Richard V. McCarthy, Decision Support Systems and Intelligent Systems, 7th ed.: Prentice-Hal! of India Privated Limited, 2007.

[3] Galit Shmueli, Nitin R. Patel, Peter C. Bruce, Data Mining for Business Intelligence: Concepts, Techniques, and Applications in Microsoft Office Excel with XLMiner, 2nd ed. Canada: John Wiley \& Sons, Inc, 2010.

[4] Joseph F. Hair, William C. Black, Barry J. Babin, Rolph E. Anderson, Multivariate Data Analysis, 7th ed. London: Pearson Education Limited, 2014.

[5] Agus Djoko Santosa, LISREL 8.7 in Research Data Processing (in Bahasa), Yogyakarta: Publisher Kepel Press, 2020.

[6] Kjersti Aas, Claudia Czado, Arnoldo Frigessi, Henrik Bakken, "Pair-copula constructions of multiple dependence," Insurance: Mathematics and Economics, vol. 44, no. 2, pp. 182-198, April 2009. [Online] Available: https://doi.org/10.1016/j.insmatheco.2007.02.001.

[7] Sayyed H. Kadhem, Aristidis K. Nikoloulopoulos, "Factor copula models for mixed data," Workshop at the Technical University of Munich, pp. 1-28, July 2019. [Online] Available: https://arxiv.org/abs/1907.07395v1.

[8] Kjersti Aas, "Pair-Copula Constructions for Financial Applications: A Review," Econometrics, vol. 4, no. 4, pp. 115, 2016. [Online] Available: https://doi.org/10.3390/econometrics4040043.

[9] Ulf Schepsmeier, "A goodness-of-fit test for regular vine copula models," Econometric Reviews, vol. 38, no. 1, pp. 25-46, 2019. [Online] Available: https://doi.org/10.1080/07474938.2016.1222231.

[10] Jörg Henseler and Marko Sarstedt, "Goodness-of-fit indices for partial least squares path modeling," Computatioal Statistics, vol. 28, pp. 565-580, 2013. [Online] Available: https://doi.org/10.1007/s00180-012-0317-1.

[11] Alberto Maydeu-Olivares, "Maximum Likelihood Estimation of Structural Equation Models for Continuous Data: Standard Errors and Goodness of Fit," Structural Equation Modeling: A Multidisciplinary Journal, vol. 24, no. 3, pp. 383-394, February 2017. [Online] Available: https://doi.org/10.1080/10705511.2016.1269606.

[12] A. Rizkiana, P. Hendikawati, "Classification of Customer Satisfaction Levels with Discriminant Analysis (in bahasa)," MIPA of Journals, vol. 38, no. 1, pp. 89-100, November 2015. [Online] Available: https://journal.unnes.ac.id/nju/index.php/JM/article/view/5490.

[13] Steffen Grønneberg, Njål Foldnes, "Covariance Model Simulation Using Regular Vines,” Psychometrika, vol. 82, no. 4, pp. 1035-1051, January 2017. [Online] Available: https://doi.org/10.1007/s11336-017-9569-6.

[14] Stefano Palminteri, Valentin Wyart, Etienne Koechlin, "The Importance of Falsification in Computational Cognitive Modeling," Trends in Cognitive Sciences, vol. 21, no. 6, pp. 425-433, June 2017. [Online] Available: https://doi.org/10.1016/j.tics.2017.03.011.

[15] L. A. Botes, W. Booysen, M. J. Mathews, M. Kleingeld, "A systematic decision support system to objectively evaluate retrospective energy efficiency modeling options," Journal of Energy in Southern Africa, vol. 30, no. 2, pp. 52-63, May 2019. [Online] Available: https://dx.doi.org/10.17159/2413-3051/2019/v30i2a5740.

[16] Amged Saleh Shkeer, Zainudin Awang, "Exploring the Items for Measuring the Marketing Information System Construct: An Exploratory Factor Analysis," International Review of Management and Marketing, vol. 9, no. 6, pp. 87-97, 2019. [Online] Available: https://doi.org/10.32479/irmm.8622.

[17] T. Husain, Maulana Ardhiansyah, "Pair-Samples T Test: Simulation Model of Financial Ratio's Measurement with Decision Support Systems (DSS) Approach," International Journal of Advanced Trends in Engineering, Science and Technology IJATEST, vol. 5, no. 4, pp. 13-17, July 2020. [Online] Available: http://www.ijatest.org/wpcontent/uploads/v5.i4.3.Pair-Samples-T-Test-Simulation-Model-of-Financial-Ratios-Measurement-with-DecisionSupport-Sytems-DSS-Approach.pdf.

[18] Indonesia Stock Exchange, December IDX, 2019. [Online] Available: https://www.idx.co.id/perusahaantercatat/aktivitas-pencatatan/.

[19] Supranto, Nandan Limakrisna, Practical Guidelines for Scientific Research for Preparing Thesis, Thesis and Dissertation (in bahasa), 5th ed. Bogor: Publisher Mitra Wacana Media, 2013.

[20] Sheridan Titman, Arthur J. Keown, John D. Martin, Financial Management: Principles and Applications, 12th ed. Boston, USA: Prentice Hall, 2013.

[21] T. Husain, "An Analysis of Modeling Audit Quality Measurement Based on Decision Support Systems (DSS)," European Journal of Scientific Exploration, vol. 2, no. 6, pp. 1-9, December 2019. [Online] Available: https://www.syniutajournals.com/index.php/EJSE/article/view/128/118. 